\title{
LEITURA COMPARATIVA DE CAMPANHA DE ALFABETIZAÇÄO CUBANA COM A DE ALFABETIZAÇÃO DA GUINÉ-BISSAU
}

\section{Lourenço Ocuni Cá}

Resumo: Neste trabalho pretendo analisar os contextos históricos do processo de alfabetização de Cuba com o da Guiné-Bissau, focalizando as principais diferenças e semelhanças entre os dois países.

Palavras-chave: Alfabetização-Cuba ; Alfabetização-Guiné-Bissau; Escrita; Oralidade

Resumen: En este trabajo pretendo analizar los contextos históricos del proceso de alfabetización de Cuba con el de la Guinea-Bissau, focalizando las principales diferenzas y semeanzas entre los dois pasises.

Palabras-llave: Alfabetización-Cuba; Alfabetización-Guinea-Bissau; Escrita; Oralidad 


\section{INTRODUÇÃO}

Pretendo investigar os contextos históricos de organização das campanhas de alfabetização em Cuba e na Guiné-Bissau que tanto se falava na Guiné, embora haja muitas diferenças essenciais entre Cuba e Guiné-Bissau, que marcam, mais profundamente do que as semelhanças, o desenvolvimento das campanhas de alfabetização e de pós-alfabetização.

Entre as mais importantes das diferenças está, sem dúvida, o caráter específico da colonização. Esta, como sabemos, em Cuba foi feita pelos espanhóis; a Guiné-Bissau sofreu a dominação portuguesa.

Diferentemente das campanhas de alfabetização na Guiné-Bissau, que se realizaram em um processo de descolonização, em Cuba a campanha se fez dentro de um processo de libertação contra uma ditadura. Em 1959, ano da "independência" revolucionária, Cuba contava com $25 \%$ da população de analfabetos. Portanto, tinha $75 \%$ da população como potencial humano suscetível de ser animador. Para a Guiné-Bissau na década de 70 (1975) $90 \%$ de analfabetos. É evidente a vantagem de um país que tinha $75 \%$ da população potencialmente preparada para participar no processo de alfabetização em relação a outro que contava com apenas 10\%. Além da percentagem de alfabetizados, existe uma diferença qualitativa entre um país e outro, qualidade que favorece a população de Cuba (FAUNDEZ, 1994: 90-103).

Em 1957, a guerrilha nas montanhas, no "Manifesto da Serra", considerava a educação como elemento essencial para o desenvolvimento e a Revolução. Foi a partir daí e naquela data que se iniciou uma campanha de alfabetização. Essa medida era radical, considerando que os dirigentes cubanos não encaravam 0 processo educacional apenas como uma questão técnica ou pedagógica, e sim como um esforço político intrinsecamente relacionado com as transformações revolucionárias da sociedade e da economia. Fidel Castro, líder teórico-prático da revolução, dava ênfase, em seus inúmeros discursos, a interconexão entre desenvolvimento e mudanças revolucionárias e a educação. Cuba desencadeou as duas frentes necessárias para acabar com 0 analfabetismo. A criação de um sistema educacional democrático, que deveria 
garantir a todas as crianças o acesso à escola e o lançamento de uma campanha de alfabetização de adultos. A campanha constituiria a resposta ao problema do analfabetismo e da educação de toda a sociedade cubana.

Depois do célebre Congresso de Cassacá, no sul da Guiné-Bissau, em fevereiro de 1964, durante o início da luta armada contra o colonialismo português, o Partido Africano para a Independência da Guiné e Cabo Verde (PAIGC) institucionalizou o que vinha planejando na área de educação. Criou escolas em toda parte nas regiões libertadas e colocou em lugar de destaque a educação entre os aspectos prioritários o combate ao colonialismo e à ignorância. Utilizou como livros tudo que dispunha como, por exemplo, cartões de embalagens de sabão ou material bélico, e como professor todo aquele que soubesse ler e escrever, respondendo à palavra de ordem de que "quem sabe deve ensinar aquele que não sabe".

No Programa Maior do PAIGC, elaborado em 1963, no capítulo da instrução e da cultura, lia-se:

1."... Reforma do ensino, desenvolvimento do ensino secundário e técnico, criação do ensino universitário e de institutos científicos e técnicos

2. Liquidação rápida do analfabetismo. Instrução primária obrigatória $e$ gratuita. Formação $e$ aperfeiçoamento urgente de quadros técnicos $e$ profissionais.

3.Liquidação total dos complexos criados pelo colonialismo, das conseqüências da cultura e exploração colonialista.

4. Na Guiné, desenvolvimento das línguas nativas e do dialeto crioulo, com a criação da escrita para essas línguas (...) Proteção e desenvolvimento da literatura e das artes nacionais.

5. Aproveitamento de todos os valores conquistados da cultura humana e universal ao serviço do progresso dos povos da Guiné e Cabo Verde. Contribuição da Cultura destes povos para o progresso da humanidade em geral".

A direção do Partido, fundamentada nestes princípios, logo após o início da luta, empenhou-se em combater o analfabetismo e a ignorância, guiada pelo princípio de Amílcar Cabral, líder

\footnotetext{
${ }^{1}$ Texto retirado de um documento do Comissariado de Estado da Educação Nacional e Cultura da República da Guiné-Bissau julho de 1976.
} 
do Partido de que "só um povo culto é um povo livre".

Tendo a especial atenção à importância da formação de quadros, médios e superiores, a direção do Partido desde o início da luta deu grande valor à questão da educação. Dessa forma, devido aos condicionalismos da guerra e à falta de quadros para o ensino, o PAIGC criou a Escola Piloto, de onde os jovens que tinham terminado a $4^{\mathrm{a}}$ ou $5^{\mathrm{a}}$ classe e que tinham dado provas de inteligência e vontade de aprender, partiam para o estrangeiro para prosseguirem os estudos.

Internatos e semi-internatos-em fevereiro de 1965 foi inaugurado o Instituto Amizade, fundado em novembro de 1964. O Instituto amizade foi criado como organização autônoma e com a finalidade de dar acolhimento, proteção e educação às crianças vítimas da guerra colonial. O seu objetivo fundamental era a formação de quadros, preparando homens responsáveis, conscientes dos seus deveres e capazes de construir um país de paz e progresso, de acordo com a linha de orientação traçada pela direção do Partido.

O Instituto Amizade concretizava os seus objetivos através da criação de jardins infantis, internatos e escolas agrícolas, onde se ministrava o ensino maternal, pré-primário, primário e secundário.

Durante o tempo da luta existiam três internatos no exterior do país e quatro nas zonas libertadas dos quais dois no leste e dois no sul da Guiné. A Escola Piloto era a escola modelo dos internatos do instituto amizade e se encontrava em Bolama, no sul do país.

Os semi-internatos foram criados no tempo da luta para reunir os alunos da $2^{\mathrm{a}}$ e $3^{\mathrm{a}}$ classes que viviam nas aldeias dispersas e não podiam entrar nos internatos por falta de lugar. Havia necessidade de reunir esses alunos, devido à impossibilidade de criar uma escola em cada aldeia. Era também uma forma de reduzir os custos de escolaridade e garantir uma melhor qualidade de ensino.

Para os alunos dos semi-internatos e outros alunos que terminavam a $4^{\mathrm{a}}$ classe ou $6^{\mathrm{a}}$ classe e não podiam continuar os seus estudos, o Comissariado da Educação estava empenhado em criar centros de educação popular integrada, para garantir a continuidade dos estudos aos alunos que concluíam a escola primária nas zonas rurais e para integrá-los no trabalho comunitário. 
A campanha de alfabetização de adultos em Cuba foi lançada em 1961. Ela foi concebida como prolongação da guerrilha e falava-se, então, de "batalha" contra o analfabetismo. Utilizou-se o modelo da revolução, não somente na estrutura, mas também na linguagem. Falava-se de campanha, brigada, batalha, mobilização, organização etc.

O processo de alfabetização tinha uma racionalidade bem clara e eficaz. Iniciava-se pela identificação da população analfabeta e prosseguia com o recrutamento dos animadores. Depois, com a formação destes e, finalmente, com a organização e execução da campanha.

Os alfabetizadores e brigadistas foram treinados durante 8 a 10 dias e a formação incluía instruções metodológicas sobre a cartilha Venceremos; sobre o manual do animador, Alfabetizemos e, por fim, sobre as orientações de campo.

A cartilha foi elaborada tendo em conta os temas e palavras relacionados diretamente a aspectos políticos, sociais e econômicos com os quais a revolução queria conscientizar os alunos. As motivações que se referiam, eram de ordem sociopolítica, que não excluíam as demais, mas predominavam sobre elas. A cartilha continha palavras como Instituto de Reforma Agrária, a terra, a milícia, Cuba não está só, o ano da Educação etc.

A campanha foi organizada e executada, começando por um plano piloto para testar os materiais, avaliar o trabalho dos jovens alfabetizados e determinar em que áreas os contra-revolucionários poderiam atuar para impedir $\mathrm{o}$ progresso da ação educativa.

A Comissão Nacional de Alfabetização enviou para o campo cerca de 100 mil escolares organizados na brigada "Conrado Benitez". Junto com os alfabetizadores, participaram animadores e supervisores.

Cada animador devia alfabetizar pelo menos duas pessoas. A unidade alfabetizadora era composta de 25 animadores, um professor de formação, um conselheiro político e o chefe da unidade. Cada província e cada município tinham uma Comissão de Coordenação, Execução e Inspeção.

Havia crescente emulação entre os municípios e, quando um era declarado 
livre do analfabetismo, a brigada deslocava-se para ajudar outros. Foram criadas inúmeras organizações e formas de mobilização para fazer avançar a campanha e obter os resultados desejados. Organizações sociais diversas colaboraram ativamente para auxiliar os participantes a freqüentar as aulas e progredir na aprendizagem da leitura e da escrita. Foram formados grupos de vanguarda que a ele cabia cumprir tarefas específicas como alfabetizar nos lugares mais distantes e/ou na periferia de Havana.

Os objetivos da campanha foram essencialmente de ordem política e econômica. Politicamente, pretendia-se "democratizar" a sociedade cubana, substituindo estrutura de classes capitalista por uma sociedade sem classes e igualitária. Economicamente, construir uma economia moderna, incorporando a ciência e a técnica à transformação da natureza e da sociedade. Isto quer dizer que a incorporação dos $25 \%$ da população à cultura escrita objetivando-se não somente a eliminar uma injustiça social-o analfabetismo - como também a permitir-lhes o acesso ao conhecimento científico, para transformar a realidade social de maneira eficaz.
Para participar desse processo de transformação, os grupos que compunham a realidade social deviam conhecer entre si pelo que eram e atuar em conjunto. A população urbana devia entrar em contato com a população rural, os operários conhecer e apreciar os camponeses. Esse elo de ligação estendia-se também aos jovens e adultos, aos homens e mulheres, que pela primeira vez participavam juntos de um processo em que todos aprendiam. Assim, a característica principal da campanha foi à participação e o diálogo entre o alfabetizador e o alfabetizando, qualquer que fosse sua idade, raça, sexo ou função social.

Uma das marcas essenciais da campanha de alfabetização cubana é a estreita relação entre a alfabetização de adultos e a escola normal. Ela inseriu-se em um processo de grande envergadura, o que se concretizou na "batalha nas seis séries iniciais". Em outras palavras, a campanha não cessou com a aprendizagem da leitura e da escrita, mas foi apenas o início de um processo educativo que tinha como objetivo imediato os seis primeiros anos de escola primária. Só com esse mínimo podia contribuir para melhorar a 
produção no trabalho e sua qualidade. Lado a lado dessa formação estava a capacitação permanente, sobretudo em nível profissional. Logo após a campanha estabeleceram-se programas para os trabalhadores, para que cursassem os seis anos do primário e, em seguida, outros estudos. Os programas que possibilitavam prosseguir os estudos nas faculdades foram elaborados pelas organizações sociais e universitárias. Essa aglutinação de saberes permitiu o acesso ao conhecimento científico formalizado que dificilmente seria superado nos demais países da subregião. Cuba se tornou em uma grande escola.

Um dos traços essenciais do sucesso da campanha de alfabetização residia fundamentalmente: a) na vontade política dos dirigentes de criar uma grande escola para transformar a sociedade, essa motivação foi aceita pelo povo. b) a organização da sociedade cubana. Depois da revolução, toda a sociedade se organizou, em centros de defesa, sindicatos, organizações de jovens, de mulheres etc. Essas organizações de massa desempenharam papel essencial em cada uma das etapas do processo educativo. c) alto índice de alfabetizados que puderam participar como animadores da campanha. d) uma infra-estrutura que possibilitava um fácil acesso às populações que deviam ser alfabetizadas e) a participação consciente da população na luta para acabar com a injustiça social, o analfabetismo e f) o fato de que Cuba é um país de tradição cultural escrita.

Proclamada a independência em 24 Setembro de 1973, o novo Estado da Guiné-Bissasu, ciente da responsabilidade, continuou empenhado no mesmo esforço em melhorar o ensino e prestou uma atenção especial à formação de professores. Foram construídas muitas escolas e a frequiência dos alunos aumentou vertiginosamente.

Após a queda do fascismo em Portugal, o que apressou a saída das tropas colonialistas, o PAIGC assumiu totalmente o controle do país em setembro de 1974. Como consequiência, impunha-se manter com a mesma clareza os princípios e os objetivos que sempre guiaram o Partido durante a luta.

Esses princípios, porém não podiam ser concretizados de uma maneira abrupta. Porque os obstáculos e as dificuldades 
eram de várias ordens. Problemas numerosos, cuja solução tinha de ser encontrada após muito estudo minucioso. $\mathrm{O}$ trabalho mais difícil estava na politização das massas estudantis dos meios urbanos, cuja mentalidade estava profundamente viciada pela presença colonialista.

Por essa razão, durante o período de transição, os anos de 1974/1975 e 1976/1977, as mudanças tinham de se introduzir passo a passo. Os programas, em particular das disciplinas de ciências exatas, mantiveram-se sem grandes alterações, nos estabelecimentos de ensino secundário. As grandes modificações se verificaram nas disciplinas de História, Geografia e de Língua Portuguesa. Essas alterações fizeram-se logo no início, pondo-se de lado os antigos compêndios e elaborando outros programas e novos esquemas de trabalho e de estudo em conformidade com a nova realidade do país.

No ensino primário, os compêndios que tinham sido elaborados durante $\mathrm{o}$ período da luta de libertação foram imediatamente adotados em todas as escolas. No entanto, durante $\mathrm{o}$ ano escolar de 1974/75, sendo reduzido o número desses livros, houve necessidade de manter alguns livros de leitura antigos, depois de uma criteriosa seleção de textos.

Em dezembro de 1975, o Comissariado de Estado da Educação e Cultura constituiu uma comissão para estudar e elaborar uma nova designação para todas as escolas do país. A nova relação apresentada foi tornada oficial em $20 \mathrm{de}$ janeiro de 1976.

As Escolas primárias-cada escola tinha uma numeração própria, conforme a região e o setor que pertencia. Algumas delas foram designadas com nomes de heróis ou datas importantes da luta de libertação nacional, como vimos no capítulo anterior.

$\mathrm{Na}$ campanha de alfabetização de adultos na Guiné-Bissau havia elementos essenciais que marcavam esse processo de alfabetização e de educação de adultos entre Cuba e Guiné-Bissau é o problema lingüístico. Enquanto que em Cuba há uma língua falada por todos os cubanos, isso não ocorre na Guiné-Bissau, onde a existência de muitas línguas dificulta não só a comunicação entre os cidadãos, como também entre o Estado e as regiões que compõem o país. Apesar de quatro línguas serem as mais 
importantes, não são do domínio de toda a população, fato este determina os limites de alfabetização. Contudo, aprender a língua materna não dá necessariamente acesso ao saber científico e técnico que permite eventualmente o desenvolvimento econômico e político do país.

Convém ressaltar a diferença nos processos de libertação e/ou independência. Em Cuba, a independência foi conquistada sem luta armada e sem ruptura violenta entre a colônia e a metrópole colonizadora. $\mathrm{Na}$ Guiné-Bissau, os dois últimos anos da luta de libertação (ocorrida entre 1963 e 1973) adquiriram o caráter de confrontos armados intensos, conseguindo-se a independência no mês de setembro de 1973.

A despeito de a independência dos dois países se realizar dentro do quadro geral de descolonização da América e da África e, por isso, terem características gerais diferentes, possuem também características específicas que vão determinar a gestão dos programas de alfabetização e de educação de adultos e de sua execução. Essas características são de ordem internacional e nacional. Nacionalmente, as realidades culturais, étnicas, de estrutura social, de população urbana e rural etc. são completamente diferentes. As relações entre o cristianismo e o animismo desempenham papel em relação à concessão de ajuda internacional.

É evidente, também que as idéias e as práticas socialistas daquela época, em nível internacional, desempenharam papel fundamental na ideologia político-social que inspirou as lutas pela independência. De fato, as leituras e as práticas de um dos movimentos de libertação fez com que essas correntes fossem diferentes em cada país e que estivessem diretamente enraizadas nas tradições culturais, ideológicas, sociais etc. que formaram as elites políticas à frente da luta pela independência. É evidente que essas tradições baseavamse em realidades diversas e, por isso, em formas diferentes de luta.

Desde a fundação do PAIGC em 1956, a educação foi considerada essencial para a própria luta e, posteriormente, para a reconstrução nacional. Nos seus últimos discursos, Amílcar Cabral, o líder político e teórico do partido, insistia no papel da educação na formação necessária do povo da GuinéBissau, sobretudo, em iniciar pela alfabetização. 
Em 1974, foram realizadas algumas atividades de alfabetização, antes da entrada dos revolucionários na capital Bissau. Com militantes e simpatizantes do partido foram programados trabalhos para alfabetizar as Forças Armadas Revolucionárias do Povo (FARP). A primeira campanha de alfabetização, em 1975, teve como beneficiários os membros das FARP e foi a única, das realizadas naquele período, que efetivamente teve êxito. Os motivos do sucesso e que em parte explicavam também o fracasso das restantes campanhas foram:

- o espírito de disciplina que existia no seio das FARP;

- a estrutura organizativa que permitiu o acesso a todos facilmente;

- a obrigação que os saldados tinham de acompanhar os cursos de

Alfabetização;

- as possibilidades de obter um emprego;

- o fato de que o exército tinha necessidade de utilizar muitos documentos.

O problema lingüístico é, sem dúvida, um dos fatores de maior influência no fracasso da primeira campanha de alfabetização da Guiné-Bissau.
Para a alfabetização da população civil, o governo criou órgãos políticoadministrativos responsável de orientar a campanha: a Comissão Nacional de Coordenação da Alfabetização (CNCA), encarregada da orientação política, e a Comissão Nacional de Alfabetização (CNA), que se responsabilizava dos aspectos técnicos. As duas comissões foram responsáveis pelas campanhas até o ano de 1978, quando se criou o Departamento de Educação de Adultos, que existe até hoje (2002).

Após uma convocação dos jovens para participar como animadores, tiveram início, em 1976, os cursos de preparação dirigidos pela equipe da CNA. Dos 120 inscritos, 60 terminaram os cursos, e foram abertos apenas 30 círculos de alfabetização na capital Bissau, que foram paulatinamente se fechando por falta de motivação das pessoas a alfabetizar. As causas apontadas foram:

- os cursos terminados de preparação, nada se fez para organizar o trabalho educativo de maneira sistemática;

- falta de apoio técnico;

- o português era totalmente estrangeiro para a grande maioria 
da população analfabeta (FAUNDEZ, 1994: 92-93).

Em 1976, apesar do fracasso da tentativa de alfabetizar em Bissau, o governo, ansioso de acabar o mais rápido possível com o analfabetismo, decidiu lançar a campanha nacional de alfabetização para a população rural majoritária do país. Duzentos jovens estudantes de diferentes regiões foram formados na capital em educação de adultos, alfabetização, saúde, agricultura e, durante as férias, dispersam-se pelo país, para participar do trabalho no campo e conviver com os camponeses. Durante o período da tarde, ensinavam os adultos a ler e escrever em português, além de transmitir-lhes conhecimentos sobre a educação sanitária, higiene, agricultura. Uma das tarefas era a de formar novos animadores nas aldeias, que deveriam continuar com $o$ trabalho educativo depois da volta dos estudantes aos cursos nos liceus em que estudavam. Da mesma maneira que a campanha na cidade, o fracasso foi total, e as causas segundo os responsáveis pela campanha, foram da seguinte ordem:

- falta de pessoal qualificado para efetuar a formação de novos membros;
- muita formação teórica e pouca prática ligada ao conhecimento da realidade concreta onde o animador devia trabalhar;

- falta de pesquisa e estudo de campo urbano e rural;

- falta de conhecimento do animador sobre outros campos (saúde, higiene, agricultura etc.);

- falta de relação entre a alfabetização e o desenvolvimento socioeconômico

No nível da Comissão Nacional de Coordenação da Alfabetização (CNCA) se verificava o seguinte:

- falta de quadros nacionais, regionais e locais formados e qualificados;

- falta de rigor organizativo e de critérios definidos nas regiões onde os animadores deviam trabalhar, e sobre as populações beneficiárias;

- falta de coordenação, de planejamento e de execução das tarefas e do acompanhamento;

- Impossibilidade dos coordenadores de irem a campo e verificar as experiências;

- desconhecimento do crioulo (língua de comunicação nacional) por parte do animador, o que impossibilitava a comunicação; 
- falta de material pedagógico e de apoioo que existia era inadaptado à realidade das populações abrangidas;

- a campanha coincidiu com a estação das chuvas, momento em que os camponeses trabalham no campo (FAUNDEZ, 1994: 94).

Detectado o fracasso, a alfabetização se converteu, em 1977/1978, em educação de base. Fato paradoxal, porque não colocava mais a ênfase na aprendizagem da leitura e da escrita, mas sim na aprendizagem de técnicas ligadas ao desenvolvimento, à agricultura, a noções de saúde e de higiene, animação sociocultural, trabalho produtivo etc. para essa formação não se empregou a comunicação escrita, e sim a comunicação oral e visual. À luz do melhoramento real da vida cotidiana das comunidades, foi uma experiência útil, já que atendia a motivações imediatas da população. Por conseguinte, os interesses em longo prazo foram desvinculados da realidade concreta.

Nesse processo de alfabetização, o governo guineense convidou o educador brasileiro, Paulo Freire a participar desde o início e a prestar assessoria pedagógica.

Depois de ter avaliado o processo de alfabetização e do período do seu "abandono" os dirigentes nacionais elaboraram e deram início a outro programa de alfabetização funcional, atribuindo assim, o fracasso do primeiro programa ao método Paulo Freire usado até então. A segunda campanha esteve, entretanto ligada à formação profissional e se realizou nos locais de trabalho dos alfabetizandos. Iniciou-se a alfabetizar nos diferentes projetos de desenvolvimento que caracterizavam uma política global do governo. Vários centros de cultura foram abertos nas fábricas, nos projetos integrados etc.

Avaliada essa segunda campanha de 1977/78, os coordenadores e animadores constataram as mesmas causas do fracasso da campanha anterior:

- falta de formação e competência dos animadores;

- falta de organização dos horários e desrespeito a eles;

- falta de material básico, como carteiras, quadros, lápis, livros;

- o problema da língua surge como a dificuldade mais marcante, uma vez que muitas vezes, os participantes não compreendiam nem o português, nem o crioulo (muitos dos animadores eram estrangeiro, brasileiros, cubanos entre outros). 
Depois do fracasso das duas primeiras campanhas, foi desencadeada uma nova ofensiva de alfabetização no ano de 1979. Foi a partir daí que se criou o Departamento de Educação de Adultos (DEA) e se reiniciaram os trabalhos de alfabetização, recrutando-se novo pessoal, desta vez assalariado. Se as campanhas anteriores haviam recebido ajuda financeira externa relativamente importante, esta última contou com o apoio material decisivo da Autoridade Sueca para o Desenvolvimento Internacional (ASDI), que lhe deu um respaldo financeiro diferente das anteriores.

Pela primeira vez, também, os soldados alfabetizados se dispuseram a dar a sua experiência a serviço da população. As diretrizes foram definidas da seguinte maneira:

- projeto-piloto para definir uma metodologia e um programa de alfabetização e pósalfabetização;

- projeto de alfabetização funcional em cálculo e gestão no leste do país e também no sul, principalmente nas Ilhas dos Bijagós.
O projeto-piloto para a definição que metodologia dotar na alfabetização e pós-alfabetização teve origem na constatação e da avaliação negativa do fracasso das campanhas anteriores. Não era possível realizar "um programa de alfabetização inspirado no método de Paulo Freire, em que os alfabetizandos aprendessem a ler e escrever a partir do descobrimento e da compreensão crítica de sua realidade social e das palavras geradoras a que estavam ligados, como povo, trabalho, luta, disciplina etc. Essa metodologia não deu os resultados previamente fixados." Ademais, a campanha tinha como língua o português, falado apenas por 10 a $15 \%$ da população. Era necessário, portanto, propor uma nova metodologia e testá-la na prática. Essa metodologia foi propugnada pela UNESCO, denominado alfabetização funcional. Assim, na nova campanha, o português seria considerado língua estrangeira e desconhecida da grande maioria da população.

Esse projeto duraria 5 anos (1980-84) e deveria permitir, além de uma nova metodologia, produzir material pedagógico e dar apoio necessário aos animadores e participantes. Neste 
sentido, seria vinculado diretamente ao sistema escolar formal.

O projeto comporia três etapas. A primeira corresponderia à fase de alfabetização. A segunda e a terceira, às fases de pós-alfabetização. Ao terminar esta última fase, os participantes obteriam o equivalente ao quarto ano primário do sistema escolar.

Como objetivo da alfabetização funcional, os círculos de cultura seriam abertos nos locais de trabalho e os alfabetizados utilizariam efetivamente os conhecimentos adquiridos. Para essa finalidade, as empresas deveriam oferecer a infraestrutura necessária para o melhor funcionamento dos círculos. Os participantes seriam dispensados do trabalho no horário de estudo, ganhando normalmente o salário. A limitação de idade dos participantes iria dos 18 aos 45 anos, e os círculos teriam um número mínimo de 15 participantes. Os cursos seriam dados em duas horas diárias, cinco dias por semana, durante seis meses.

Uma pesquisa realizada nas fábricas constatou o resultado negativo, considerando que elas (fábricas) não estavam interessadas na alfabetização dos seus operários. Contanto, foram abertos quatro círculos: três em Bissau e um no interior do país. Os resultados foram insatisfatórios, devido, sobretudo ao problema da língua, o português.

Em 1981, decidiu-se começar a ensinar a ler e escrever em línguas vernaculares. Com a assessoria da UNESCO e de outros organismos internacionais. Deu-se início a um estudo das línguas mais importantes (em termos de números expressivos dos falantes) do país, basicamente o crioulo, falado por $44 \%$ da população. Essa seria a língua veicular e instrumento eficaz para a comunicação e criação da unidade nacional. Porque o crioulo não pertence a nenhuma das etnias que compõem a Guiné-Bissau.

Elaborou-se uma gramática e um léxico de 3 mil palavras, o que serviu de base para uma proposta de uma escrita corrente e simples, que estaria ao alcance dos alfabetizandos.

Em 1982, os materiais foram experimentados em doze centros, sendo adaptados e refeitos depois da experiência. Em 1985/86, abriram-se 59 círculos, com 1.662 participantes. 
Paralelamente a esse programa e como parte dele, criaram-se no leste e no norte do país círculos de cultura para ensinar o cálculo e a gestão em projetos de desenvolvimento econômico.

Depois do resultado êxitoso da experiência de alfabetização em crioulo, teve início, em 1982, o estudo de uma segunda língua, o fula, falado por cerca de $23 \%$ da população, especialmente no leste do país. Como já se falava a língua fula nos países vizinhos e onde sobre ela havia elaborado sua escrita, tornou-se fácil começar a preparação do material didático. Em 1983/84, abriram-se 20 círculos com mais de 300 participantes, número que passou a 689 nos anos de 1985/86.

A campanha estava inserida em um processo de longo prazo, tanto por sua duração (5 anos), quanto pela relação com a educação formal. No que diz respeito à primeira fase, comportava duas fases, a alfabetização e após alfabetização. Esta segunda fase era de suma importância para realizar de fato a passagem da oralidade que caracteriza a cultura africana à escrita.
O processo de alfabetização de adultos estava em uma primeira fase e deveria comportar muitas outras. O objetivo era alfabetizar em línguas vernaculares para em segundo momento, em português, aprendido como segundo língua, ou como terceira, se fosse o caso. Da mesma maneira em que a alfabetização na língua materna não dá necessariamente um instrumento de acesso à ciência e à técnica "universal", as quais devem ser dominadas pelo cidadão para contribuir no processo de desenvolvimento socioeconômico e político do país. Teoricamente, qualquer língua levaria ao acesso à ciência e às técnicas, no entanto, na prática isso exige um longo percurso para apropriação de uma lógica e de um vocábulo específicos. Significaria, também despesas excessivas para esse empreendimento. Traduzir livros técnicos e científicos requer um gasto gigantesco, a Guiné-Bissau não estava em condições de o fazer. Tempo e economia são, portanto, imperativos para considerar que uma língua "científica" seja ensinada e dominada, para que o acesso à ciência e à técnica possam criar condições de desenvolvimento do país. 
O fracasso da campanha de alfabetização da Guiné-Bissau se deve ao problema da língua e da desorganização, que sintetizavam por sua vez, o problema de diversos grupos etnolingüísticos em um único país. Como outros motivos, aparecia também a falta de uma fase de pósalfabetização, como foi feito em Cuba, que iria preparar a passagem para os programas de educação básica da instrução formal de adultos, a carência de recursos financeiros e de "animadores culturais" preparados. Os organizadores da campanha quiseram explorar a euforia revolucionária da vitória sobre o poder colonial para transmitir rápida e amplamente as técnicas de leitura e da escrita a toda população da Guiné-Bissau e fazê-la participar da reconstrução nacional. As razões desta iniciativa foram às palavras geradoras para todo $\mathrm{o}$ território nacional e a condução central da campanha a partir da capital. Ficava a cargo da habilidade individual dos alfabetizadores adaptar as palavras geradoras às circunstâncias de vida e motivar para a campanha uma população que nem sempre compreendia a necessidade de aprender a ler e a escrever em razão da vida que levava.
Esta tarefa exigia demais da parte dos alfabetizadores. De igual forma, a propaganda para a campanha por parte das organizações de massas do partido e do governo não teve o resultado esperado. O exemplo da alfabetização de massa em Cuba, ao qual serviria de referência na Guiné-Bissau, não se repetiu nesse país da costa ocidental da África. Em Cuba, o "Movimento de 25 de julho" havia iniciado mesmo antes da independência, um amplo processo de conscientização junto à população, mais do que foi feito no exército de libertação do PAIGC face aos antagonismos tribais existentes durante e após a guerra de libertação. Em consequiência disto, em Cuba pósrevolucionária de 1962 aprenderam a ler e a escrever mesmo os cidadãos que ainda não tinham nenhuma possibilidade de utilização imediata das técnicas de leitura e escrita, mas que, devido ao seu grau de politização e ao caráter massivo da campanha, participavam ativamente. Ademais, em Cuba existia uma base de comunicação nacional através da língua espanhola, que faltava à GuinéBissau.

O caráter político da educação ficou basicamente mantido para a campanha reelaboradora, mesmo com risco de se 
deixar de lado a problemática étnica, cultural e social dos interessados.

Os colaboradores do Departamento de Educação de Adultos do Ministério da Educação eram favoráveis, nos seus documentos básicos, a uma alfabetização vinculada ao local de trabalho como vimos anteriormente.

O princípio de vinculação ao local de trabalho do Projeto-Piloto expressavase também na oferta de um "Programa de Cálculo e de Gestão". Em Contuboel, no leste do país, em um projeto comunitário agrícola de melhoria do cultivo de arroz, esse programa despertou interesse entre os membros da comunidade do que a própria alfabetização. A determinação exata das distâncias entre as estacas, a relação entre as medidas de capacidade e as unidades de peso eram tarefas urgentes no decurso do trabalho diário, que foram levadas em consideração no âmbito do ProjetoPiloto.

O projeto piloto vinha se orientando assim implicitamente pelo princípio da alfabetização funcional incentivado desde há muito anos pela UNESCO. $\mathrm{Na}$ realização deste princípio repetiam-se também abusos da "funcionalidade" como o da exclusão daquele que tinha mais de 45 anos do processo de alfabetização.

Face a esse princípio, o de alfabetização funcional, o sistema de Paulo Freire, que tinha como objetivo o desenvolvimento da personalidade total e que foi seguido de forma experimental com o apoio do próprio educador durante a campanha de 1975-76, parece ter ficado para o segundo plano. A participação em grande número dos especialistas da UNESCO na instrução de coordenadores comprovava essa tendência. No entanto, considerando o alto endividamento do país, a necessidade de eliminação dos prejuízos da guerra e frente ao baixo nível de produção da agricultura, da pequena empresa e da indústria, o experimento de alfabetização a ser testado nos anos subseqüentes levaria em conta o conjunto de necessidades econômicas imediatas da GuinéBissau. 


\section{REFERÊNCIAS BIBLIOGRÁFICAS}

DOCUMENTO DO COMISSARIADO

DE ESTADO DA EDUCAÇÃO

NACIONAL E CULTURA DA REPÚBLICA DA GUINÉ-BISSAU. Julho 1976.

FAUNDEZ, A. A expansão da escrita na África e na América Latina. Análise de um processo de alfabetização. Rio de Janeiro: Paz e Terra, 1994.

GERHARDT, H.P.. Alfabetização na Guiné-Bissau. Educação \& Sociedade, Campinas, n. 8, 1981.

PÉREZ, C. Hacia el perfeccionamento del trabajo de dirección de la escuela. Habana: Editorial Pueblo y Educacacíon, 1986.

MINISTÉRIO DE EDUCACIÓN DE CUBA Y ORGANIZACIÓN DE ESTADOS IBERO-AMERICANOS. Sistema Educativo Nacional de Cuba. Informe realizado por Miguel Varela Hernandez et al. Habana, 1995. 